TRACKING STUDIES ON THE EFFECTS OF MAGNET MULTIPOLES ON THE APERTURE OF THE RHIC HEAVY ION COLLIDER*

G.F. Dell and G. Parzen

BNL- -36566

Brookhaven National Laboratory

Upton, New York 11973

\title{
DE85 013282
}

\section{Abstract}

Tracking studies including the effects of random multipoles resuliing from construction errors have been made for RHIC with two independent tracking programs at three different tunes. The studies were made using ten different sets of random errors for each of the programs. The aperture was defined as the worst case, and the results of the two programs are in good agreement. A second set of studies was made for which the number of dipoles was doubled to determine whether doubling the number of independent random errors results in a reduction of the effects or random multipoles. The results for the two cases, one dipole per half cell and two dipoles per half cell, indicate there is little difference in dynamlc aperture.

\section{Introduction}

The present paper describes tracking studies on RHIC, the Relativistic Heavy Ion Collider being designed at Brookhaven National Laboratory. The ar Lerator is an 1ntersecting storage ring designe. to accelerate fully stripped ions from $D^{+}$to $A$. co energies of $100 \mathrm{GeV} / a m u$. The lattice design of this a:celerator is described in another paper at thi, conference. ${ }^{1}$ The goal of the present study is to assess single particle dynamics with and without random field errors in a region of tune space that is being considered for operation. The studies have been made with two independent tracking programs that include the effects of magnet multipoles. The first program is PATRICIA ${ }^{2}$, and the second is ORBIT $^{3}$. The results obtained with the two programs have been in consistent agreement.

The latt1ce consists of six arcs each having twelve cells with $90^{\circ}$ phase advance. Tune changes are made by vary1ng the strengths of the insertion quadrupoles and thus require rematching with a design program such as SYNCH. The nominal dipole field is $3.26 \mathrm{~T}$; the dipoles and quadrupoies of the $r: ! 1$ s have coil ID's of $8.0 \mathrm{~cm}$. Beam collisions at $0^{\circ}$ are made possible by a set of dipoles on either side of the intersection point. The dipoles nearest the intersection are common to both beams and must have large apertures (coil ID = $20 \mathrm{~cm})$. Only one beam passes through the second $\mathrm{di}-$ pole, but since this can be a region of high $B$, the bore of these dipoles is also enlarged (coll ID = $10 \mathrm{~cm})$. In addition, the first three quadrupoles on either side of the intersection are in a region of maximum $B$ and have increased bores with coil ID's of $13 \mathrm{~cm}$.

The multipoles used in this study are random and were generated with a simple model assuming 0.002 inch rms variations in the thickness, width, radial position and azimuthal position of each current block. The magnitude of the random errors for a fixed construction tolerance depends on the coil ID. The random errors have been scaled as $1 /\left(r / r_{0}\right)(n+1)$ where $r_{0}$ is the nominal coil radius and $I$ is the assumed radius. The multipoles for the nominal coll radil are listed in Table 1 .

*Work performed under the auspices of the U.S. Department of Energy.
Systematic sextupoles located at the centers of the quadrupoles in the arcs have been adjusted to give a chromaticity of zero in both the $x$ and $y$ planes. The emittances in both planes were equal. All particles were started with $x^{\prime}=y^{\prime}=0.0$. The displacements $x$ and $y$, with $y=\left(B_{y} / B_{x}\right)^{\frac{1}{2}} \cdot x$, were increased in fixed steps until an amplitude was reached where the particle stopped within 400 turns. Test runs with 1000 turns produced the same stability l1mit as that for the 400 turn runs, but 200 turn runs sometimes gave greater stability limits. It was concluded that 400 turn runs gave reliable results, and such runs have been used throughout this study.

The $a_{1}$ and $b_{1}$ random errors were excluded from the study. Only random errors were used with the errors being selerted from a gaussian distribution that was truncated at $+3 \sigma$. The region of tune selected for this study is $28.800 \leq v \leq 28.833$ in both the $x$ and $y$ planes. The upper tune is a $5 / 6$ resonance, and the lower tune is a $4 / 5$ resonance.

Table $l$ (a) Random multipoles in RHIC quadrupoles

\begin{tabular}{rlll}
\hline $\mathrm{n}$ & \multicolumn{1}{c}{$\begin{array}{c}\mathrm{11s} \\
(\mathrm{m}-\mathrm{n})\end{array}$} & $\begin{array}{c}\mathrm{Q1-Q3} \\
(\mathrm{m}-\mathrm{n})\end{array}$ & $\begin{array}{c}\mathrm{Q} 4-\mathrm{Q} 8 \\
(\mathrm{~m}-\mathrm{n})\end{array}$ \\
\hline 1 & 0.0 & 0.0 & 0.0 \\
2 & $4.35 \mathrm{E}-1$ & $1.58 \mathrm{E}-1$ & $4.35 \mathrm{E}-1$ \\
3 & $1.09 \mathrm{E}+1$ & $1.79 \mathrm{E}+0$ & $1.09 \mathrm{E}+1$ \\
4 & $3.24 \mathrm{E}+2$ & $3.07 \mathrm{E}+1$ & $3.24 \mathrm{E}+2$ \\
5 & $9.35 \mathrm{E}+3$ & $4.64 \mathrm{E}+2$ & $9.35 \mathrm{E}+3$ \\
6 & $2.63 \mathrm{E}+5$ & $7.30 \mathrm{E}+3$ & $2.63 \mathrm{E}+5$ \\
7 & $7.26 \mathrm{E}+6$ & $1.21 \mathrm{E}+5$ & $7.26 \mathrm{E}+6$ \\
8 & $1.97 \mathrm{E}+8$ & $1.86 \mathrm{E}+6$ & $1.97 \mathrm{E}+8$ \\
9 & $5.28 \mathrm{E}+9$ & $2.71 \mathrm{E}+7$ & $5.28 \mathrm{E}+9$ \\
10 & $1.40 \mathrm{E}+11$ & $4.06 \mathrm{E}+8$ & $1.40 \mathrm{E}+11$ \\
\hline
\end{tabular}

Table 1(b) Random multipoles in RHIC dipoles

\begin{tabular}{rlll}
\hline $\mathrm{n}$ & $\begin{array}{l}\mathrm{Ce} 11 \mathrm{~s} \\
\left(\mathrm{~m}^{-\mathrm{n}}\right)\end{array}$ & $\begin{array}{l}\mathrm{BC} 2 \\
(\mathrm{~m}-\mathrm{n})\end{array}$ & $\begin{array}{l}\mathrm{BC1} \\
\left(\mathrm{m}^{-n}\right)\end{array}$ \\
\hline 1 & 0.0 & 0.0 & 0.0 \\
2 & $4.75 \mathrm{E}-1$ & $3.06 \mathrm{E}-1$ & $5.13 \mathrm{E}-2$ \\
3 & $1.48 \mathrm{E}+1$ & $7.62 \mathrm{E}+0$ & $6.39 \mathrm{E}-1$ \\
4 & $4.23 \mathrm{E}+2$ & $1.75 \mathrm{E}+2$ & $7.31 \mathrm{E}+0$ \\
5 & $1.10 \mathrm{E}+4$ & $3.62 \mathrm{E}+3$ & $7.61 \mathrm{E}+1$ \\
6 & $2.96 \mathrm{E}+5$ & $7.80 \mathrm{E}+4$ & $8.18 \mathrm{E}+2$ \\
7 & $7.06 \mathrm{E}+6$ & $1.48 \mathrm{E}+6$ & $7.81 \mathrm{E}+3$ \\
8 & $1.79 \mathrm{E}+8$ & $3.02 \mathrm{E}+7$ & $7.91 \mathrm{E}+4$ \\
9 & $4.37 \mathrm{E}+9$ & $5.90 \mathrm{E}+8$ & $7.73 \mathrm{E}+5$ \\
10 & $1.06 \mathrm{E}+11$ & $1.14 \mathrm{E}+10$ & $7.51 \mathrm{E}+6$ \\
\hline
\end{tabular}

\section{Results} $30 \pi \mathrm{mm}$ mradians and corresponds to more than $39 \mathrm{~mm}$ at the center of the cell quadrupoles. Inclusion of magnetic multipoles reduces the dynamic aperture. The goal of the present study is to find a region of cune space and a combination of multipoles (magnet ID) that gives the required dynamic aperture.

ferent sets of random errors for each tracking program.
With no multipoles other than chromaticity correcting sextupoles, the dynamic aperture exceeded

All tracking studies have been made for ten dif-

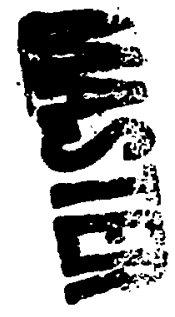




\section{DISCLAIMER}

This report was prepared as an account of work sponsored by an agency of the United States Government. Neither the United States Government nor any agency thereof, nor any of their employees, makes any warranty, express or implied, or assumes any legal liability or responsibility for the accuracy, completeness, or usefulness of any information, apparatus, product, or process disclosed, or represents that its use would not infringe privately owned rights. Reference herein to any specific commercial product, process, or service by trade name, trademark, manufacturer, or otherwise does not necessarily ccnstitute or imply its endorsement, recommendation, or favoring by the United States Government or any agency thereof. The views and opinions of authors expressed herein do not necessarily state or reflect those of the United States Government or any agency thereof. 
All ten cases had to satisfy the aperture requirement before a configuration was considered to be acceptable. The tunes at which tracking studies were made are shown in Fig. 1. They include a point outside the region of prime interest, a point near the upper end of the region of interest, and a point near the lower end of the region of interest. For all points studied, the tune decreases as the particle emittance increases.

The steps $\Delta x$ used for tracking with PATRICIA (run on the CRAY X-MP at LLNL) were $~ 0.6 \mathrm{~mm}$, while in the interest of economy, the steps used with ORBIT (run on the BNL CDC 7600) were 2mm. At $\triangle P / P=0.0$ the operating points " $A$ ", " $B$ ", and " $C$ " were found with ORBIT to have stability limits of $15 \pm 1,19 \pm 1$, and $13+1 \mathrm{~mm}$, respectively, while with PAT̃RICIA these $1 \mathrm{im}-$ its were $15.6+0.3,19.4+0.3$, and $15.6+0.3 \mathrm{~mm}$, respectively. The stability Iimits found with the two programs overlap for points " $A$ " and " $B$ " while there is some disagreement for point " $C$ ". Sample histograms of the aperture determination for ten runs having different random number sequences are shown in Fig. 2 .

The effects of removing random multipoles was investigated with ORBIT at point " $A$ ". Removal of the random error multipoles in the magnets of the arcs (regular cells) increased the stability limit from $15+1$ to $21 \pm 1$ min at $\Delta \mathrm{P} / \mathrm{P}=0.0$. Removing the error multipoles in al1 BC2 dipoles, the second beam crassing dipole on either side of the intersection, increased the stability limf from $15 \pm 1$ mm to $17+$ mm. This suggests that when $\beta^{\star}=6 \mathrm{~m}$ at the intersection, the random error multipoles in the arcs play a more important role than do those in the insertions. It was also found at point " $A$ " that increasing the coil radius of the $\mathrm{BC} 2$ dipoles by $30 \%$ and the coll radius of the arc dipoles by $20 \%$ would increase the stability limit $\mathrm{f}$ rom $15 \pm 1 \mathrm{~mm}$ to $19 \pm 1 \mathrm{~mm}$ at $\Delta \mathrm{P} / \mathrm{P}=0.0$.

Similar studies have been made with PATRICIA. As increasing the coil radius increases the magnet size and cost, the goal was to find the largest stability IImit consistent with the smallest increase in coil ID.

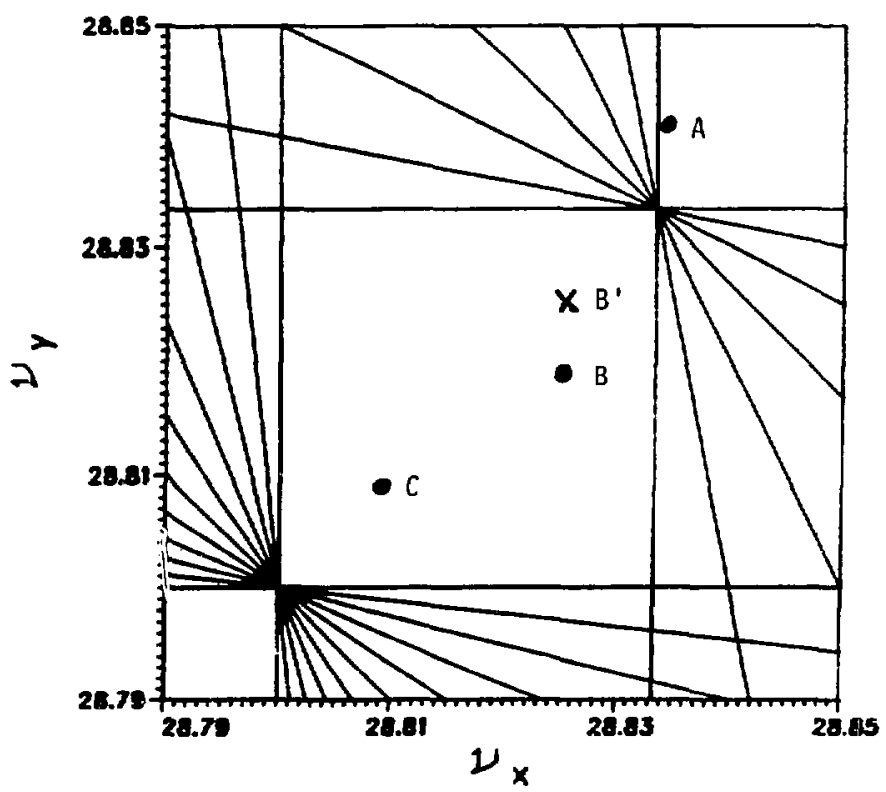

FIg. 1 Tunes $\left(v_{x}, v_{y}\right)$ at whlch tracking studies were made. " $A$ " $=(28.834,28.841), " B$ " $=(28.825,28.819)$, "B'" = $(28.825,28.825)$ (split dipoles), and "C" = $(28.809,28.809)$.

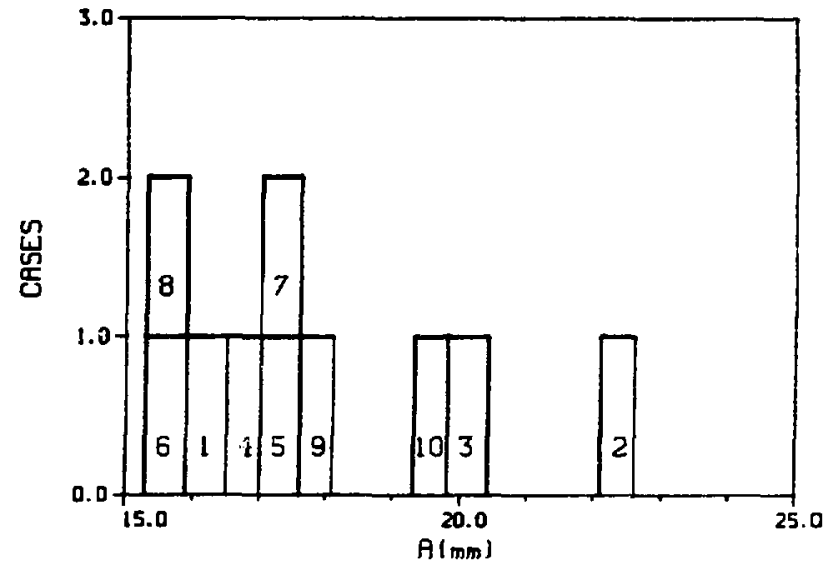

Fig. 2(a) The distribution of stabllity limits found with PATRICIA at point "A", $v_{x}=28.834, v_{y}=28.841$ for ten different sets of random multipole errors. The worst case is $15.6 \pm 0.3 \mathrm{~mm}$. Cell geometry: independent thin lens kicks at each end of every dipole-one dipole per half cell.

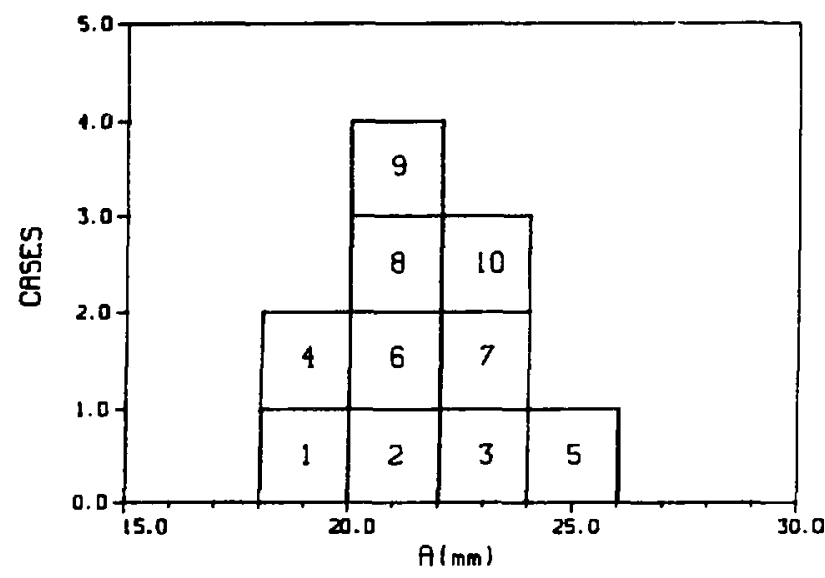

Fig. 2(b) The distribution of stability limits found with ORBIT at point " $B$ ", $v_{x}=28.825, v_{y}=28.819$ for ten different sets of random multipale errors. The worst case is $19+1 \mathrm{~mm}$. Cell geometry: equal thin lens kicks at each̆ end of a dipole--one dipole per half cell.

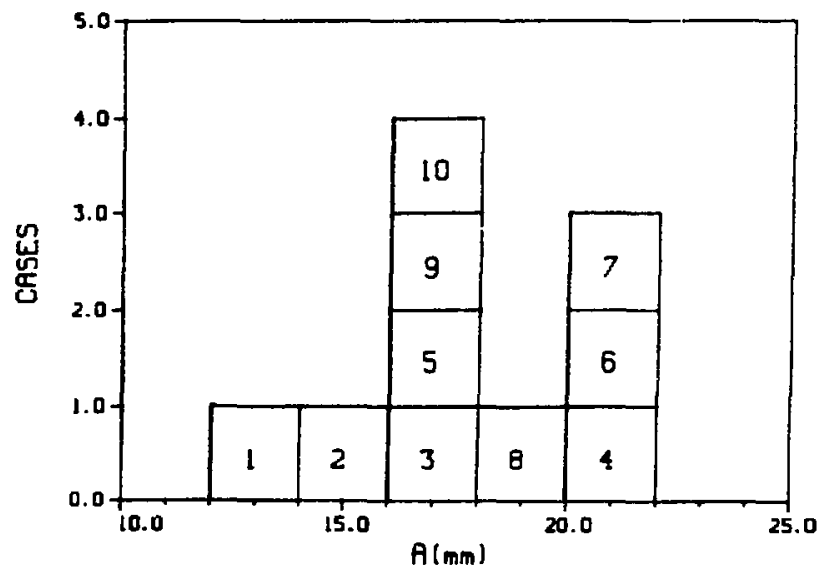

Fig. 2(c) The distribution of stability limits found with ORBIT at point " $C$ " $v_{x}=28.809, v_{y}=28.809$ for ten different sets of random multipole errors. The worst case is $13 \pm 1 \mathrm{~mm}$. Cell geometry: equal thin lens kicks at each end of a dipole--one dipole per half cell. 


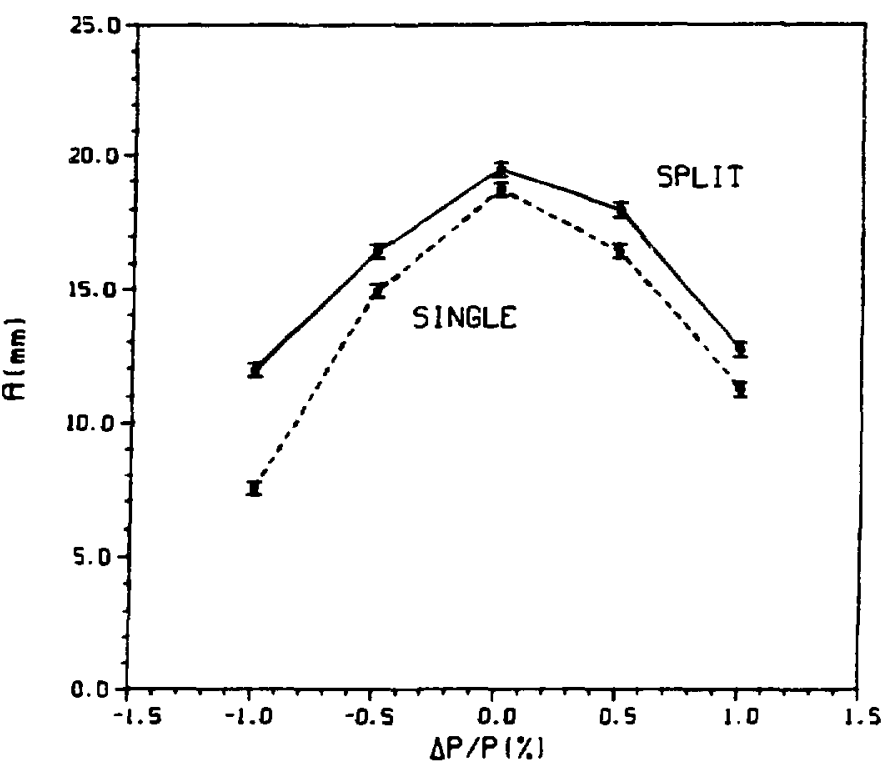

Fig. 3 Momentum scans at points "B" (single dipole per half cell) and " $B$ " ( $t$ wo dipoles per half cell). Values represent the worst case for ten different sets of randor multipole errors.

This study was also made at point "A". A stability limit of $19+0.3 \mathrm{~mm}$ was obtained when the arc quadrupoles had their nominal coil ID and the radii of all other elements were increased by $10 \%$. In addition, $\left(a_{4}, b_{4}\right)$ was set to zero in all other elements other than the three quadrupoles $Q_{1}$ to $Q_{3}$ near the crossing point--in these elements $\left(a_{5}, b_{5}\right)$ was set to zero. Further study of the upper allowed IImits of the decapole and dodecapole errors have not been made; the main emphasis has been to determine the maximum stability limit when all elements have their nominal ID's.

At point "B" a stability limit of 19 mm was obtained with both programs when all magnets had their nominal radii and random multipole errors. A momentum scan was made at this tune; the results appear in Fig. 3. As before, tracking runs were made with ten different sets of random multipole errors, and the worst case was used as the stability limit. A stability 1 Imit of $19 \mathrm{~mm}(6 \sigma)$ was obtained at $\Delta P / P=0.0$, and the stability $11 \mathrm{mit}$ at $\Delta P / P= \pm 0.5 \%$ is reduced-by $23 \mathrm{~mm}$ to $5 \sigma$. This is the naximum momentum spread of the stored beam. During acceleration the momentum spread will increase to $\sim 1.2 \%$ at transition, but as this will be a temporary situation, the $12 \mathrm{~mm}(4 \sigma)$ stabllity limit is not considered unreasonable.

\section{Split Dipoles}

A sacond set of runs has been made to determine whether or not increasing the number of dipoles improves the aperture--thether the effects of the random multiples scale as $1 / \sqrt{2 \mathrm{~N}}$, with $N$ being the number of dipoles. In all the previous studies there was a multipole kick at each end of every dipole. The ORBIT program uses the same multipole at each end of the dipole, while the default version of PATRICIA assigns a different multipole to each end of a dipole. In the second study the dipoles were split in two with a multipole element at each end of every half dipole. In addition, PATRICIA was changed so that the multipoles at boch ends of a dipole could be the same or different. By using split dipoles with the option of

- having the same multipole at both ends, the sequence of random multipoles was unchanged from what it had been in the first study. The stability limit was not determined for point " $\mathrm{A}$ ". For point " $\mathrm{C}$ " the stability limit is the same at $\Delta P / P=0.0$ with one or two dipoles per half cell. At points "B" (single) and "B"' (two) the stability limits at $\Delta \mathrm{P} / \mathrm{P}=0.0 \mathrm{differ}$ by $0.6 \mathrm{~mm}$ and are considered to be consistent. The results of the "B"' scan also appear in Fig. 3. No significant difference has been found between having one or two dipoles per half cell. is doubling the number of units increases the cost, thist does not seem to be a promising avenue for improving the performance of the lattice.

\section{Conclusions}

The data presented in this report represent the present status of the aperture studies on RHIC. The results are not final; more studies will be performed that will look at alternate working points at the effects of including $a_{1}, b_{1}$, at the effects of systematic multipoles, and at corrector systems. The manner in which beim-beam tune shift and amplitude dependent tune shift combine has not been fully evaluated.

Finally, the random errors used in this study were generated from a rather simple model using an assumed rms coil displacement of 0.002 inches and are to be considered as reasonable but not final. Tracking studies are intended to explore the sensitivity to particular random multipole errors so that efforts can be made to reduce those multipole errors during the construction phase. Once magnet construction is started a set of actual random miltipole errors will be obtained, and magnet shuffling may be used to reduce the effects of a single undesirable multipole.

\section{References}

1. S. Y. Lee, Present Conference.

2. H. Wiedemann, PEP-220, Stanford Linear Accelerator Center, September, 1976.

3. G. Parzen, Brookhaven National Laboratory, Unpublished. 